\title{
Alexandre Correia: Reminiscências
}

\author{
Manoel de Figueiredo Ferraz \\ Livre-Docente de Direito Romano, da Fac. de \\ Direito da Universidade de São Paulo
}

A Faculdade de Direito da Universidade de São Paulo, em reuniảo solene prestou comovida homenagem à memória de um dos seus mais ilustres Mestres: ALEXANDRE CORREIA.

$\mathrm{Na}$ oportunidade, pelo sodalício falou o eminente Professor Ruy Barbosa Nogueira, que traçou o Perfil de Humanista do homenageado; ademais, o Governo Federal outorgou «post-mortem» a mais alta condecoração do Mérito Educacional, àquele que em vida não só simbolizou o amor à cultura humanística, como engrandeceu com o seu saber, as mais altas tradições jurídicas do país.

Referiu-se o conferencista ao pródromo de sua carreira, guando interessando-se pela filosofia política o Prof. Alexandre Correia, defendeu em Louvain a sua primeira tese intitulada «Política de Joseph de Maistre», obtendo com ele o doutorado no «Institut Supérior de Philosophie Saint Thomas», da Universidade.

O Mestre-Conferencista, marca e traz à colação sentimental aquele cuja vida e obra bem se poderia sintetizar como «lumina et lucerna iuris» dos tempos presentes.

Mas, tenho para mim que algumas passagens das atividades extracurriculares passariam ao olvido, senão registradas pelos que de perto o conheceram.

De Ribeirão Preto, onde conquistara a cadeira de grego, passou o Professor Alexandre a residir em São Paulo, na Avenida Rodrigues Alves, uma das principais artërias do bairro de Vila Mariana.

Os moradores, já que a maioria era de estrangeiros, se conheciam e eram conhecidos por nós que, vindos de Mococa, lá residíamos.

Algumas figuras marcaram, indelevelmente, a minha juventude: Marrey Júnior, popular politico, eleito Prefeito da Capital e que não tomara posse em razão do movimento revolucionário de 30; Arthur Aguiar Whitaker, espírito claro, culto e de fino trato, ocupara a Presidência da Assembléia Legislativa do Estado, no governo Júlio Pres- 
tes: o Professor Eduardo Monteiro - uma das glórias da medicina paulista, e numa quadra abaixo o Professor Alexandre Correia.

O pequeno movimento da artéria, apenas abalada pela passagem do famoso «Bonde Santo Amaro», permitia aos moradores individualizar os seus personagens mais destacados.

O Professor Alexandre Correia, vindo de Ribeirão Preto, oncle conquistara a cadeira de grego, no Ginásio Estadual, chegara a capital com fama de homem sábio e sisudo no seu relacionamento. Fez-se amigo dos meus familiares e suas visitas eram marcadas pelo respeito que a todos infundia. Limitavamo-nos a ouví-lo apenas, e procuravamos adivinhar na nossa ingenuidade infantil, o porquê da fama e talento; é que a sua conversação se destacava para as coisas terrenas - árvores, passarinhos, etc. Falava-se na sua austeridade de comportamento e seriedade no trato com os alunos. Numa cidade que aindla esquentava os seus músculos para o futuro deslocamento como grande Metrópole, a sua figura era singular. Em passadas largas, comedido no comprimento, a de corpo esguio, de feições avermelhadas. de porte saxônico, era notado e respeitado.

Notícias de suas atividades, no serão íntimo de nossa família, a todos surpreendia e agitava.

Uma delas, grande surpresa, e que a todos angustiou: a do anúncio de sua morte em um dos jornais. Sim!!! Alunos de determinado estabelecimento de ensino resolveram pregar a assustadora «peça». Vingavam-se da sua rigidez no critério de notas, com a publicação do seu falecimento. Desusado movimento na pacata artéria; carros se aproximando de sua residência, pessoas na calçada consternadas com o «passamento» do Mestre. Aos poucos desanuviou-se o ambiente. Sorridente, na porta, D. Filhinha sua esposa, explicava aos atônitos visitantes dos tradicionais «meus pêsames» que tropeçavam em coroas de flores, o episódio debitado aos alunos que não tendo alcançado as «notas» que entendiam injustas valeram-se do inusitado expediente.

O Professor Alexandre resolveu pessoalmente desfazer o equivoco e dirigiu-se ao jornal que noticiara o evento. Conta-se que um dos «repórteres», o Prof. Basileu Garcia, mais tarde Mestre desta Casa, ao vê-lo subir as escadarias do prédio, sentiu um calafrio na espinha: presenciava espavorido o «ressurgimento» do morto.

Assim, conhecemos Alexandre Correia e mal sabiamos que c teríamos de enfrentar na carreira que abraçariamos - do Gínásio do Estado ao concurso para a cátedra de Direito Romano da Academia, um passo apenas. Mas, foi lá que, precisamente, iríamos reconhecer o «Mestre Temido», cuja fama de irritável e pouco amigo dos estudantes, marcaria época nos anais do Largo São Francisco.

Em plena guerra, tentávamos o exame de ingresso; o latim era simplesmente o terror do noviciado. A banca, vejam só: seus integrantes, Alexandre Correia, Lino Leme e Mário Masagão. Pior impossível! Alguns pais, compadecidos, escoltavam os filhos àqueit 
autêntico templo onde fatalmente, sucumbiriam. Os pré-calouros, quietos, tentando soletrar alguma passagem de Cícero e partes da gramática, aninhavam-se nos cantos como ovelhas à espera dos lobos.

Das provas, exauridos, cabisbaixos, trêmulos magotes de candidatos deixavam o recinto: «Deu para passar?»

- Acho que as minhas silabadas me prejudicaram... - Bem, se não passar, tentarei em outra Faculdade, mas enfrentar essa banca, nunca mais!... Prefiro ser convocado para brigar contra os alemães!

$\mathrm{E}$ assim, os contínuos queixumes da inevitável desdita!

Anunciados os resultados, os aprovados submetiam-se ao trote tradicional. E os jornais não só anunciavam os aprovados, mas ainđa com laudatórias insinuações - «O trote dos sábios».

Mas, ledo engano. Havia que se enfrentar a mais difícil etapa da Academia; assistir, tentar compreender, e fato inédito, passar na cadeira diabólica: Direito Romano. Seu titular: Alexandre Correia. Desnecessário maiores explicações. Compêndio não havia; os mais afortunados, filhos de advogados e magistrados, surgiam sobraçando o «Foignet» - consequiência, edição esgotada, nenhuma importação!

A figura do titular de Romano, na aula, infundia respeito, medo ou melhor, pavor. E já de pronto, os textos do Corpus Iuris Civilis, citados em latim, que o Mestre com o sorriso sarcástico - «não há por que traduzir, já que os senhores conhecem perfeitamente, o latim....»

Marcados os exames, os grupos se manifestavam: bem, com o Cazuza, o Vampré, nenhum problema. Mas, não adianta: o Direito Romano, como dizia Santo Agostinho «me terruit....»

Aos poucos, exibiam-se em sonoras citações dos textos, os alunos da primeira fila: Ruy Barbosa Nogueira, Cícero Dantas Lopes, Aloysio Ferraz Pereira, Jaime Silva Telles, Alexandre Thiollier, Pedro Conde, Camilo Ascar que galgariam justa fama na profissão. Os outros. bem, os outros, quedavam-se mudos. Presença sim, esta obrigatória. $\bar{E}$ verdade que os movimentos grevistas se sucediam - O Ditador, por isso e por aquilo, pelos seus atos de arbitrio, levava os estudantes para o pátio e para as ruas. Para Alexandre Correia, derrota da França, atos do Ditador, política dos estudantes, pouco se lhe dava.

A sua aula estava dada e a matéria considerada devidamente explanada. Mas, o ano corria e os exames com as notas anunciadas eram como bombardas a aumentar o pânico - de zero a cinco, as maiores; para cima poucas. O felizardo aquinhoado com cinco ou seis já desfilava com ares de Papiniano. E infundia respeito, uma quase veneração - obteve seis em Romano? Cumprimentos para o «sábio»; desalento, para os demais!

Praticamente, poucos conseguiam atingir a grande meta: escapar do exame oral - estes, os quase «morituri te salunt». Era como espe- 
rada sentença de morte. Os mais tímidos eram confortados pelos amigos próximos, que julgando assistir as provas por «osmose» transfeririam para o colega os seus ensinamentos.

No «purgatório», a espera da convocação, já com o ponto escolhido - a surpresa pelo seu ineditismo.

- O seu ponto é ... o $\mathrm{n}^{\circ}$ 198: «conditio triticaria».

- O senhor pode começar.

$\mathrm{E}$ o aluno lívido, quase que em alucinação - «conditio triticaria» - Mestre é... é... é... O tempo escoava e rápido. A «equipe de apoio» mais surpresa ainda... «conditio triticaria», que raio de pergunta é essa? - É um atentado, uma violência... ferindo até direi. tos individuais, acrescentavam os mais ousados.

Bem, mais um zero no lúgubre quadro do primeiro ano!

Assim, rigido, presente e justo porque realmente o ponto fora dado e nesse dia talvez a estudantada estaria enfrentando os «esbirros da Ditadura» a tétrica convocação para a segunda época.

Assim, a passagem do Professor Correia pela Academia.

Mas, o pavor não se infundia apenas no corpo discente. Concurso para a Congregação; o Alexandre está na banca? Pois, olhe dizia o candidato, embora com tese pronta, é de se pensar... E muitos desistiam - o medo, fenômeno psíquico se alastrava. Muitos e muitos deixavam de enfrentar banca de concurso. O Alexandre vai examinar? Os mais ousados compareciam e os alunos também. Era a grande oportunidade. O Alexandre na banca, plenário cheio... E lá vinha o Mestre com a Tese nas mãos para o primeiro entrevero: «A sua tese está imperfeita, a partir do título. . e a saraivada de observações!

- Já que o senhor citou Platão e Aristóteles, por que não o fez no original? Mas, dou-lhe a oportunidade: aqui está o texto; leia-o e traduza-o. E o candidato de beca ou de casaca, esbaforido:

- Mas, Mestre não domino o latim e o grego suficientemente para ... e não terminava a justificativa.

Findo o concurso, aflitos e inconsoláveis os familiares ...

- Mas, isto é um absurdo... Querer que se leia em grego; se fosse em latim, vá lá...

E a estudantada regozijava e se permitia comentar: é, concluíram, com o Alexandre na banca é melhor escolher outra escola, para aluno e professor...

Afinal, o Mestre Alexandre não distinguia, aluno e candidato a professor com termos de absoluta igualdade. $\mathrm{E}$ um ou outro gaiato acrescentava: mas, não é isto que chamam de «eqüidade»? 
Há um provérbio chinês que diz ser Bom Professor é melhor dc que várias bibliotecas.

Quando da sua aposentadoria, o Professor Alexandre já residia à Rua Martiniano de Carvalho, ou melhor a sua casa era um apêndice de sua valiosa biblioteca.

Lá surgiriam os famosos serões, quando professor, amigos e colegas reuniam-se, para estudos e diálogos sob a batuta do Mestre.

Cursos de Filosofia, Humanística, Línguas e até de Direito Romano; incansável, o Professor preparava a sua $2^{\text {a }}$ edição completa da Summa Teológica; ademais, continuava suas pesquisas sobre os Pré-socráticos.

Foi a grande oportunidade que Alexandre Correia teve de se aproximar dos seus antigos alunos; cada um deles trazia algumas reminiscências da Academia, jocosas muitas, reais ou irreais, que motivava sorrisos e saudades do passado. Afinal, a vida acadêmica não se encerrava e a intelectual prosseguia.

A última aula realizou-se com grande pompa; alunos, ex-alunos e amigos lotavam o Salão Nobre - uma consagração! A intelectualidade brasileira presente! Era a sua última aparição em público.

Fui testemunha do extremo carinho dispensado aos que o procuravam; em meio à conversa, citações de Homero, no original. Não entendiamos o grego, mas louvávamos a prodigiosa memória.

Em poucas linhas, o perfil do professor - glória da intelectual1dade brasileira.

Quando das homenagens que a nossa Academia prestou à memória do Prof. Emérito Alexandre Correia, coube ao eminente Prof. Ruy Barbosa Nogueira, traçar-lhe o perfil de Humanista.

Nos decênios dos anos 40, ainda aluno, participei de concurso instituido pela Associação dos Antigos Alunos da Faculdade, sob o tema: A vida do Professor Crispiniano Soares.

O objetivo dos promotores do Concurso era trazer do olvido, uma das figuras mais singulares dos primeiros anos de vida da Academia do Largo São Francisco. Para um simples acadêmico a empresa não se apresentava fácil; dados, informes incompletos, aliados às dıficuldades de se fixar na vida da pacata cidade de após independência, a personalidade do primeiro lente de Direito Romano da nossa sempre velha e nova Academia - que marcou época em seus anais, a partir de sua exótica vestimenta; calças brancas, paletó preto e o uso contínuo do chinó a cobrir-lhe a calva. 


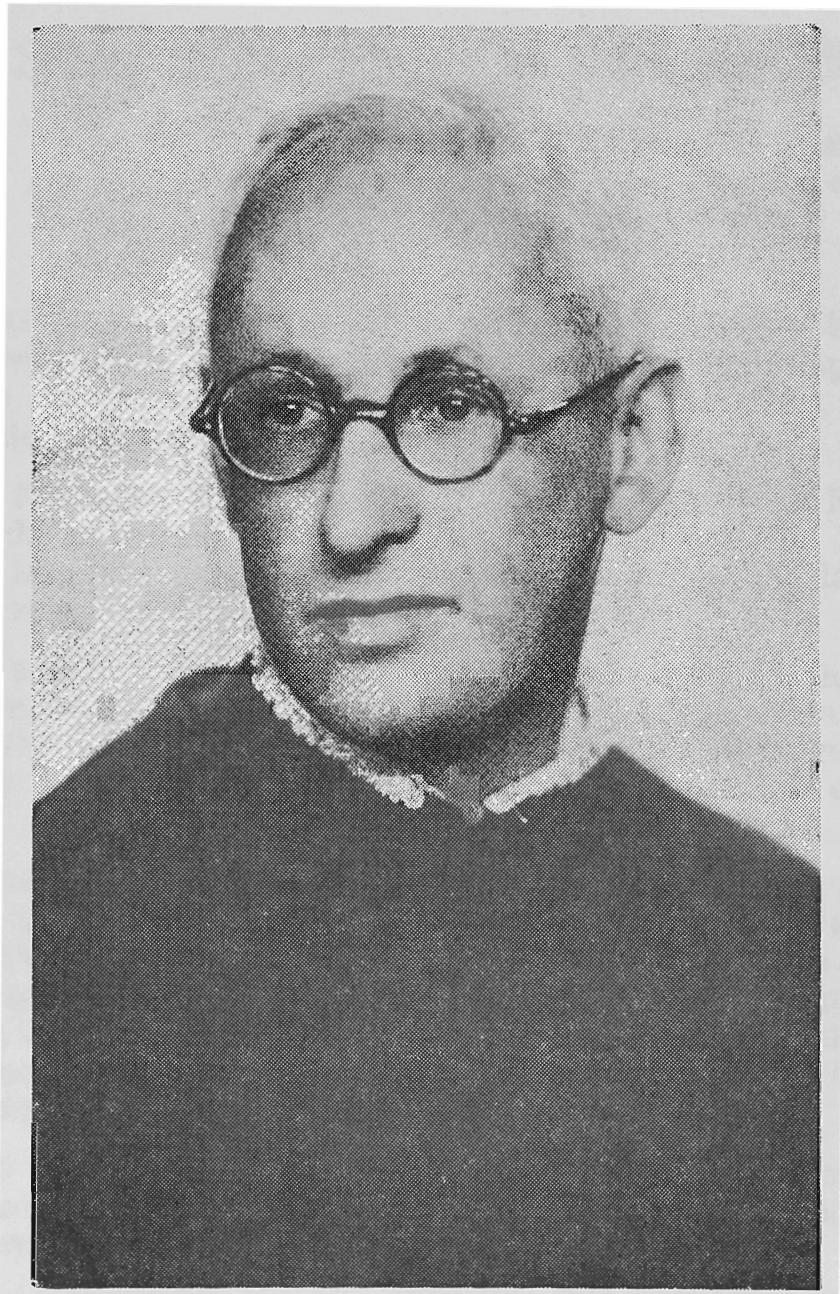

Professor Doutor Alexandre Correia 